\title{
The grey zone of thrombocytopenia: accuracy of automated analyser vs manual method
}

\begin{abstract}
Introduction: Most common cause of platelet not being accurately counted by automated analyser is the presence of giant platelet and platelet satellitism. Another cause in north-east region is, Harris platelet syndrome most common cause of inherited thrombocytopenia is characterised by low platelet count, high MPV and absence of bleeding.
\end{abstract}

Objective: To compare platelet count results of automated analyser with manual (PBS examination and neubauer chamber counting).

Result: A total of 3803 patients were investigated for haematological parameters; 564 are males and 233 are females. On automation, 797 cases were thrombocytopenic (445 mild; 257 moderate; 95 severe thrombocytopenia) whereas by manual method only 423 cases were thrombocytopenic ( 238 mild; 125 moderate; 60 severe thrombocytopenia).

Conclusion: Due to various reasons of false low platelet count by automated analyser, manual examination by peripheral blood smear should always be considered whose platelet count is low by automation.

Keywords: thrombocytopenia, automated analyser
Volume 6 Issue 2 - 2018

\section{Gayatri Gogoi, Shreya Kar,Ashim Manta, Srimanta Madhab Baruah}

Department of pathology, Assam Medical College and Hospital, India

Correspondence: Gayatri Gogoi, Department of pathology, Assam Medical College and Hospital, Dibrugarh-786002, India, Tel 9435030084 ,

Email gayatrigogoi303@gmail.com, kar.shreya1991@gmail.com

Received: February 07, 2018 | Published: March 19, 2018
Abbreviations: PBS, peripheral blood smear; MPV, mean platelet volume; IGPD's, inherited giant platelet disorders

\section{Introduction}

Reliability of platelet estimation is essential to make clinical decision specially when platelet transfusion is considered (Figure 1). It is widely accepted that automation in hematology yield high precision and accuracy in haematological parameters in normal individuals. ${ }^{1-5}$ However, automated counting is still very controversial in cases of thrombocytopenic patients in which other small particles could generate electrical or optical signals that are similar to platelets, such as debris and red cell fragments. ${ }^{4,6-11}$

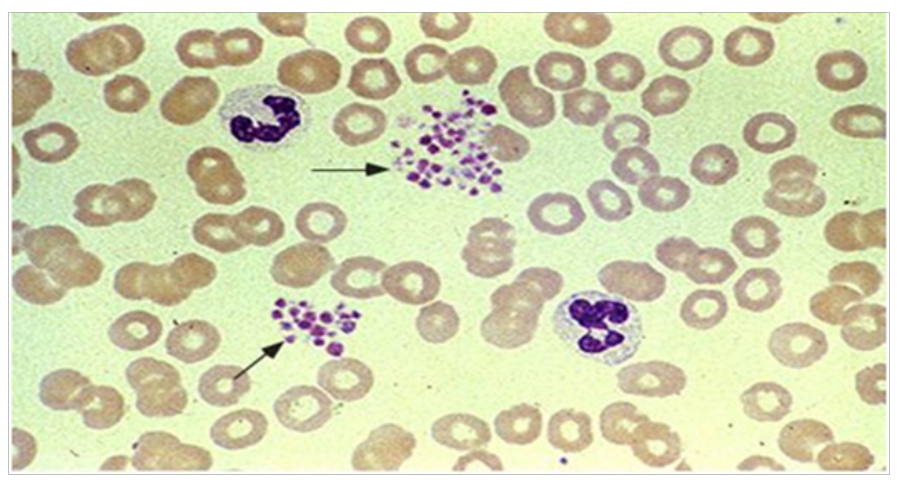

Figure I Platelet Clumping.

Most common cause of platelet not being accurately counted by automated analyser is the presence of giant platelet and platelet satellitism (Figure 2). Pseudothrombocytopenia remains a challenge in the haematological laboratory. The pre-analytical problem that platelets tend to easily aggregate in vitro, giving rise to lower platelet counts, has been known since ethylenediamine-tetra acetic acid
EDTA and automated platelet counting procedures were introduced in the haematological laboratory.

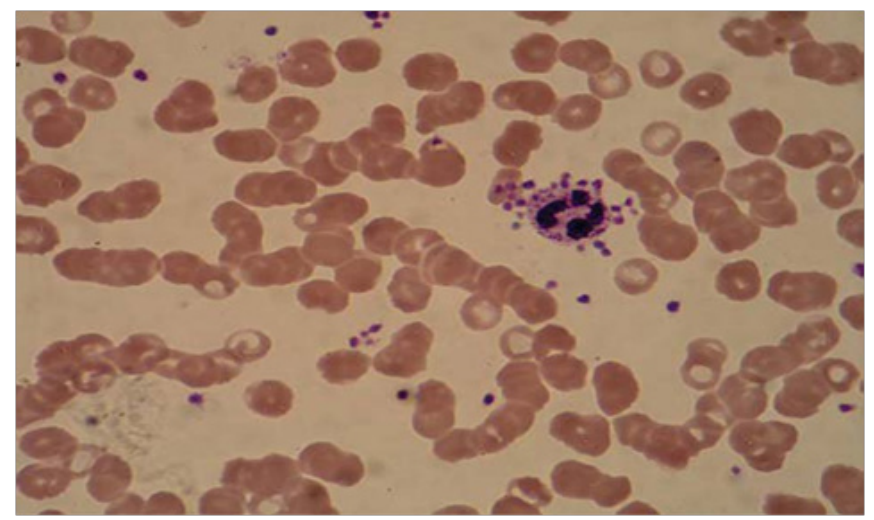

Figure 2 Platelet Satellitism.

Currently, IGPD's (Inherited giant platelet disorders) are classified into 4 broad sub-categories: the first category is based on structural defects of platelets; the second category is based on pathognomonic peripheral blood morphologic findings like neutrophil inclusions; the third category is based on associations with clinical and systemic manifestations; the fourth category is considered a benign anomaly such as Mediterranean macrothrombocytopenia. ${ }^{12}$ Very recently, another cohort of population from north eastern part of Indian subcontinent, were found to have Harris platelet syndrome or asymptomatic constitutional macrothrombocytopenia. ${ }^{13}$ This syndrome is recently described by Naina et al. ${ }^{13}$ Harris platelet syndrome is characterised by absent bleeding symptoms, mild to severe thrombocytopenia (platelets rarely $<50 \times 10^{9} / \mathrm{L}$ ) with giant platelets (Figure 3) (Mean platelet volume $>10 \mathrm{fL}$ ) and normal platelet aggregation study with absent MYH9 mutation. ${ }^{14,15}$ Their low platelet count causes concern while administering chemotherapy or undertaking surgical procedure. 
Therefore blood films have been commonly used for platelet estimation in settings of low platelet count.

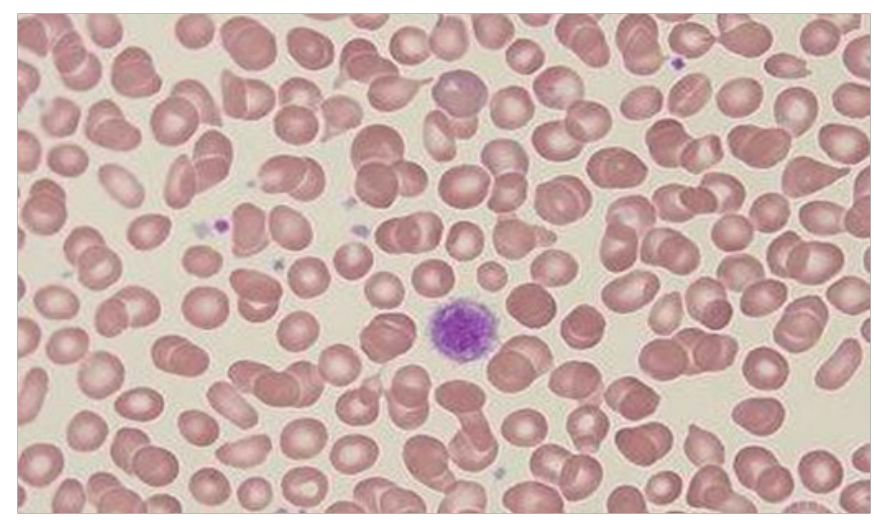

Figure 3 Giant Platelet.

Beside manual estimation of platelet count, blood film evaluation provides additional assessment of platelet size, shape, granulation, and analysis of phenomena such as aggregation or platelet satellitism.

\section{Materials and method}

This study was conducted in department of pathology, $\mathrm{AMCH}$, Dibrugarh from $1^{\text {st }}$ May, 2017 to $31^{\text {st }}$ July, 2017 (3 months). All the blood samples in EDTA vial having low platelet count $\left(<150 \times 10^{9} \mathrm{~L}^{-1}\right)$ by automated analyser is evaluated by PBS examination and Neubauer chamber counting. Thrombocytopenia was graded as mild (100$\left.150 \times 10^{9} \mathrm{~L}^{-1}\right)$, moderate $\left(50-100 \times 10^{9} \mathrm{~L}^{-1}\right)$ and severe $\left(<50 \times 10^{9} \mathrm{~L}^{-1}\right)$ (Figure 4).

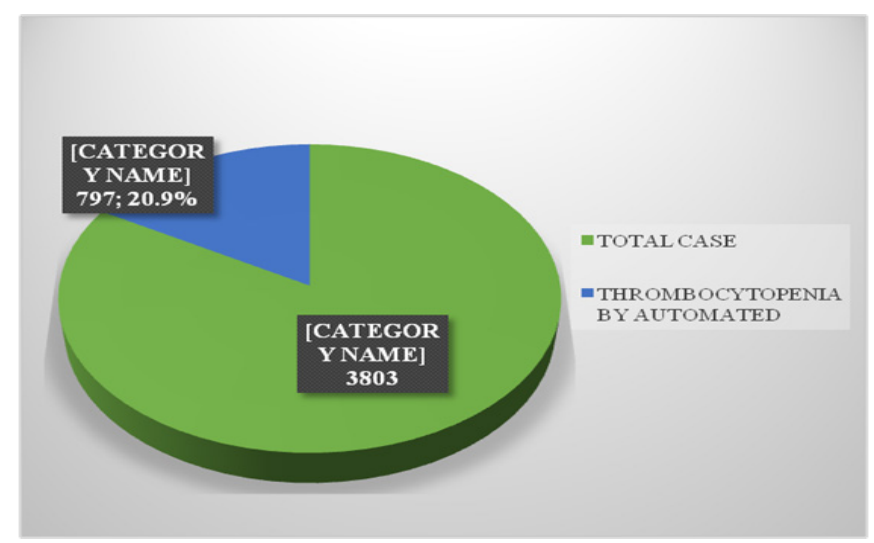

Figure 4 Chart showing percentage of thrombocytopenic samples by automated method.

\section{Results}

We have demonstrated that manual platelet count estimate is reproducible in trained competent hands when using a standardized methodology. A total of 3803 patients were investigated for haematological parameters for time period of 3 months i.e. $1^{\text {st }}$ May to $31^{\text {st }}$ July, 2017 in department of Pathology, Assam Medical College and Hospital, Dibrugarh. Out of 3803 cases, 797 cases were thrombocytopenic $(20.9 \%)$ on automation in contrast to 423 (11.1\%) on manual method (Figure 5) (Figure 6). Out of these 797 thrombocytopenic cases, 564 are males (70.8\%) and $233(29.2 \%)$ are females. Highest number of thrombocytopenia cases i.e. 180 cases
$(22.5 \%)$ falls in the age group of $30-40$ years followed by 152 cases (19\%) in 20-30 years (Figure 7).

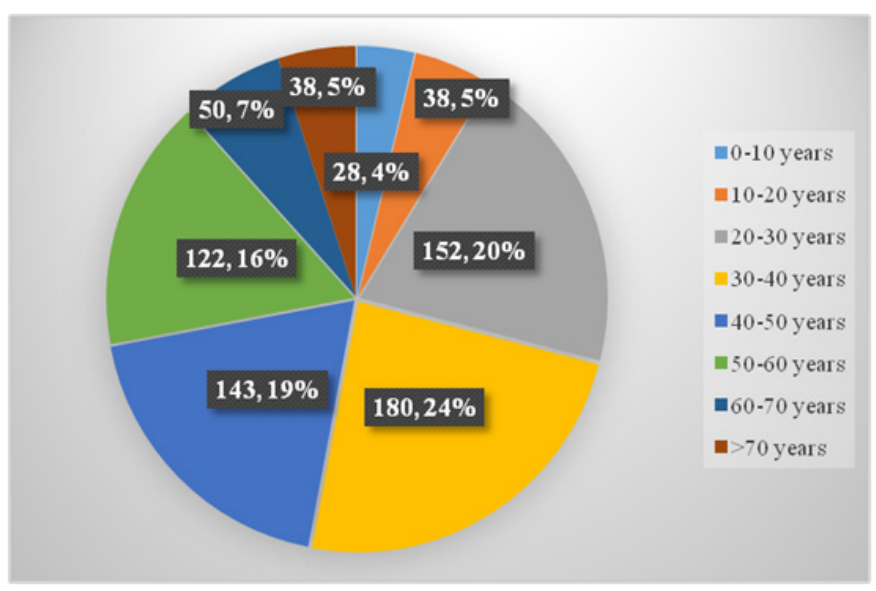

Figure 5 Age wise distribution of thrombocytopenic cases.

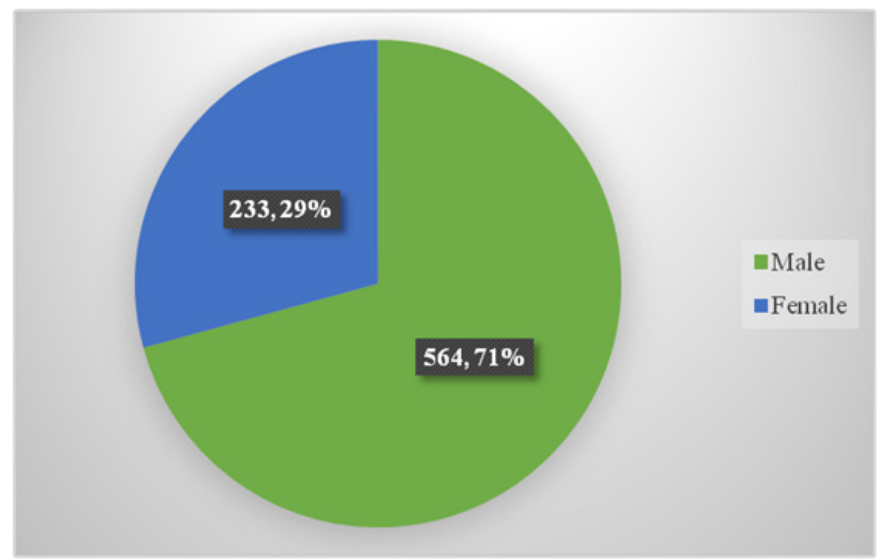

Figure 6 Gender wise distribution of thrombocytopenic cases.

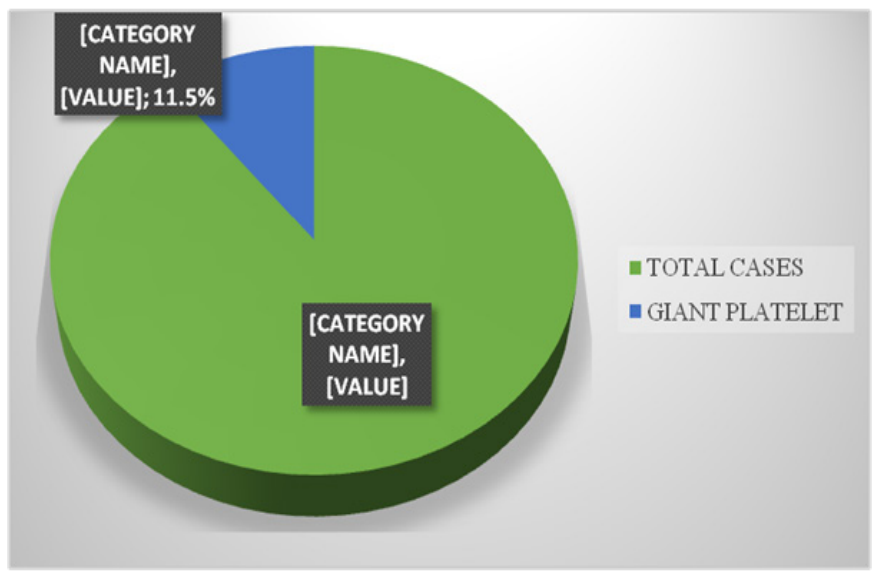

Figure 7 Samples with giant platelet.

These 797 thrombocytopenic cases were subjected to manual examination. On manual examination only 423 samples out of 797 were thrombocytopenic i.e. (11.1\% of total cases). So the remaining 374 cases $(9.8 \%$ of total cases) which were previously diagnosed as 
thrombocytopenic on automation but adequate in manual method forms the GREY ZONE AREA (Figure 8).

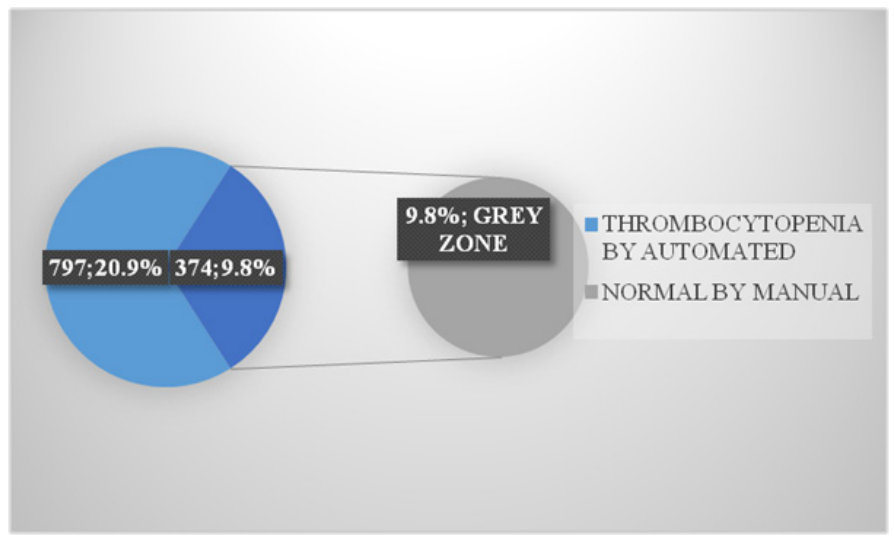

Figure 8 Grey zone of thrombocytopenia.

We have divided the thrombocytopenic cases according to severity i.e. mild, moderate and severe thrombocytopenia (Figure 9). On automation, 797 cases were thrombocytopenic (445 mild; 257 moderate; 95 severe thrombocytopenia) whereas by manual method only 423 cases were thrombocytopenic ( 238 mild; 125 moderate; 60 severe thrombocytopenia). 451 cases i.e. $11.8 \%$ cases were found to have high MPV. On manual examination of 757 thrombocytopenic samples we found 438 (11.5\% of total cases) cases with giant platelet. So this $11.5 \%$ of thrombocytopenic cases with giant platelet syndrome should be genetically studied for MYH9 for its further categorization. Most of the transition occurred in mild and moderate thrombocytopenic group which were converted to normal range of platelet when examined manually.

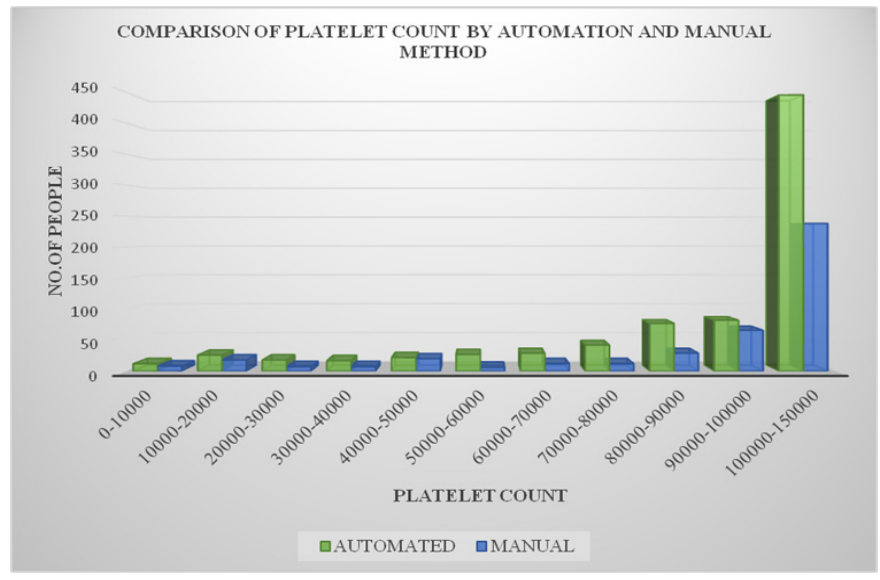

Figure 9 Comparison of platelet count by automated and manual method.

\section{Discussion}

In our study we found the positive predictive value of automated analyser being $52 \%$. We have also found that a large number of cases i.e. 374 samples $(9.8 \%)$ labelled as thrombocytopenia (by automated method) is converted to normal platelet range by manual forming the grey zone area of thrombocytopenia indicating a definite need to examine the blood sample both by automated and manual (PBS and Neubauer chamber counting) method (Figure 10).

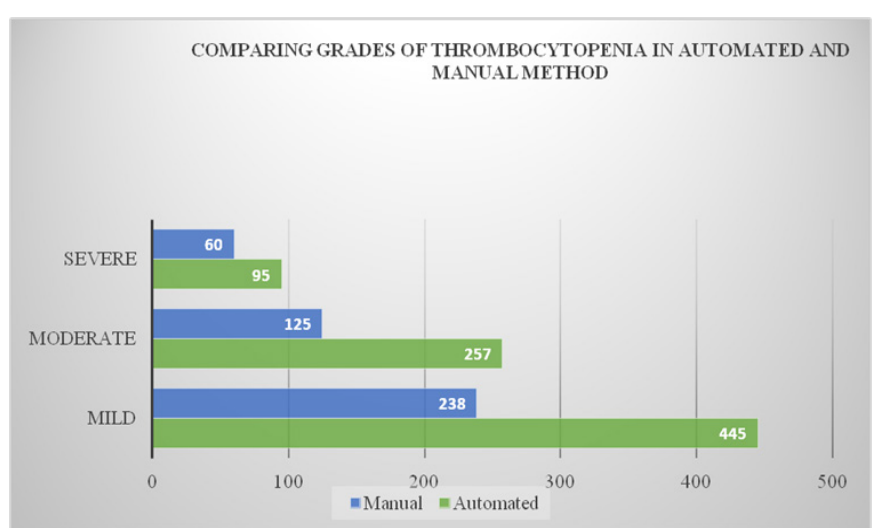

Figure 10 Comparison of grades of thrombocytopenia in automated and manual method.

One study done by Naina et $\mathrm{a}^{[13]}$ showed high prevalence of asymptomatic constitutional macro thrombocytopenia in eastern and north eastern region of India, so using only automated haematological analyser will be not suitable for population of these areas. It is extremely important to recognise and diagnose HPS (Harris Platelet Syndrome), as nearly one out of six people in certain areas of the subcontinent possess the anomaly. Lack of awareness and misdiagnoses create confusion and medical mistakes. During dengue outbreaks-when platelet counts fall-patients who have HPS are unnecessarily hospitalised. Also, low platelet counts discourage surgeons from operating on patients, apprehending that cuts will not heal.

Haematologists at Vellore's Christian Medical College (CMC) were the first to notice that many people from eastern and northeastern India, Bangladesh, Bhutan and Nepal have low platelet counts. During screening of blood donors from eastern India doctors found that approximately one out of six of them had a platelet count below $150 \times 10^{9} \mathrm{~L}^{-1}$ (which was low compared with platelet counts of people of south India) but high MPV and without any symptom related to thrombocytopenia but they were rejected for failing to meet the cutoff for pre-donation platelet counts and because they constituted a huge donor pool, their rejection caused a setback to blood donations. Average platelet count was low when compared with platelet counts of people in southern India. So there is a definite need to standardize the normal platelet range in these regions where prevalence of asymptomatic constitutional macro thrombocytopenia is high.

438 (11.5\% of total cases) showed giant platelet in peripheral blood smear should be genetically studied for MYH9 to classify it into various categories of Inherited Giant Platelet disorder so that we can estimate the actual number of cases of Harris platelet syndrome. Due to various reasons of false low platelet count by automated analyser such as giant platelet, platelet satellitism, micro clot etc, manual examination by peripheral blood smear should always be considered whose platelet count is low by automation as large numbers of cases labelled as thrombocytopenia by automated haematology analyser are within normal range when examined manually (the grey zone of thrombocytopenia; $9.8 \%$ cases in our study) cause confusion in clinical diagnosis and management. So both clinicians and laboratory personals should be aware of this fact and should give due emphasis on manual method as well to establish accuracy and search for causes when possible. 


\section{Conclusion}

There is a need for development of consensus regarding normal range of platelet in north east region as there is high prevalence of asymptomatic constitutional macro thrombocytopenia. Also there is a need of genetic study to identify MYH9 gene mutation to classify such cases of thrombocytopenia into various categories of Inherited Giant Platelet disorder

\section{Acknowledgements}

We thank all the laboratory technicians of Assam Medical College and Hospital for their immense help and support.

\section{Conflict of interest}

The author declares that there is none of the conflicts.

\section{References}

1. Ross DW, Bentley SA. Evaluation of an automated hematology system (Technicon H-1). Arch Pathol Lab Med. 1986;110(9):803-808.

2. Cornbleet PJ, Myrick D, Judkins S, et al. Evaluation of the CELL-DYN 3000 differential. Am J Clin Pathol. 1992;98(6):603-614.

3. Arkin CF. Quality control and standardization in the hematology laboratory. In: Bick RL editor. Hematology: clinical and laboratory practice. St Louis: Mosby; 1993. p. 17-37.

4. Dickerhoff R, Von Ruecker A. Enumeration of platelets by multiparameter flow cytometry using platelet-specific antibodies and fluorescent reference particles. Clin Lab Haematol. 1995;17(2):163-172.

5. Jones RG, Faust AM, Matthews RA. Quality team approach in evaluating three automated hematology analyzers with five-part differential capability. Am J Clin Pathol. 1995;103(2):159-166.
6. Ault KA. Platelet counting: Is there room for improvement? $L a b$ Hematol. 1996;(2):139-143.

7. Mayer K, Chin B, Magnes J, et al. Automated platelet counters: a comparative evaluation of latest instrumentation. Am J Clin Pathol. 1980;74(2):135-150.

8. Ross DW, Ayscue L, Gulley M. Automated platelet counts: accuracy, precision, and range. Am J Clin Pathol. 1980;74(2):151-156.

9. Kjeldsberg CR. Principles of hematologic examination. In: Lee GR, Bithell TC, editors. Wintrobe's Clinical Hematology. 9th ed. Philadelphia: Lea \& Febiger; 1993. p. 11-12.

10. Kunicka JE, Fischer G, Murphy J, et al. Improved platelet counting using two-dimensional laser light scatter. Am J Clin Pathol. 2000;114(2):283289.

11. Hanseler E, Fehr J, Keller H. Estimation of the lower limits of manual and automated platelet counting. Am J Clin Pathol. 1996;105(6):782787.

12. Mhawech P, Saleem A. Inherited Giant Platelet Disorders: Classification and Literature Review. Am J Clin Pathol. 2000;113(2):176-190.

13. Naina H, Nair S, Daniel D, et al. Asymptomatic constitutional macro thrombocytopenia among West Bengal blood donors. Am J Med. 2002;112(9):742-743.

14. Naina HV, Nair SC, Harris S, et al. Harris syndrome a geographic perspective. J Thromb Haemost. 2005;3(11):2581-2582.

15. Naina HV, Harris S. Platelet and red blood cell indices in Harris platelet syndrome. Platelets. 2010;21(4):303-306. 